\title{
ТЕХНОЛОГИИ ИНТЕРНЕТА ВЕЩЕЙ (ІОТ) В ТРАНСПОРТНОМ КОМПЛЕКСЕ И ИХ ЭКОНОМИЧЕСКИЕ ПОСЛЕДСТВИЯ
}

\author{
(c) 2020 Гулый Илья Михайлович \\ кандидат экономических наук, доцент \\ Петербургский государственный университет путей сообщения Императора Александра I, \\ Россия, Санкт-Петербург \\ E-mail: ilya.guliy@mail.ru
}

Актуальность и экономическая эффективность внедрения технологий цифровой трансформации, четвертой промышленной революции, одним из которых выступает Интернет вещей (IoT), предопределяют необходимость их проектного описания, анализа, проведения технико-экономической оценки. В статье дается обоснование преимуществ внедрения технологий Интернета вещей в сфере транспорта. Систематизированы задачи, решаемые посредством внедрения ІоТ на транспорте; сформулирован основной функционал ІоТ на примере железнодорожных перевозок. С помощью статистических данных Росстата дается оценка масштабов распространения отдельных цифровых технологий, связанных с Интернетом вещей, в российском транспортном комплексе, в том числе в сфере железнодорожного транспорта. Обозначены основные проекты стратегии цифровой трансформации Российских железных дорог, связанные с ІоТ, и их экономические последствия.

Ключевые слова: Интернет вещей, IоT, Internet of things, цифровой транспорт, Российские железные дороги.

\section{Введение}

«Интернет вещей» (IoT) - важнейшая сквозная технология современного развития компаний всех отраслей экономики. Возможность подключения большого числа устройств, физических активов к сети Интернет и друг к другу выводит ІоТ из технологии потребительского использования в ранг технологий широкого коммерческого применения, с помощью которой создаются новые продукты, услуги, технологии, бизнес-модели и оптимизируются существующие.

\section{Результаты исследований}

Интернет вещей (Internet of Things, IoT) это глобальная инфраструктура цифровой экономики, обеспечивающая возможность предоставления услуг путем соединения друг с другом датчиками и исполнительными механизмами (актуаторами) физических и виртуальных «вещей» на основе информационнокоммуникационных технологий. Использование полученных данных в режиме реального времени позволяет проводить оптимизацию процессов и объектов, а применение актуаторов (обратная связь с ними) дает возможность осуществлять оптимизацию без существенных затрат [5]. Благодаря внедрению технологий IоT сокращаются расходы, растет производительность труда и доходность компаний, отраслей и в итоге всей мировой экономики.

IоT обеспечивает подключение всех видов устройств к сети Интернет и друг к другу. При этом, с одной стороны, объединяются «умные», «подключенные» продукты и услуги, с другой, данные от оборудования, машин, транспортных средств, механизмов собираются и объединяются между собой для повышения эффективности процессов [1].

В транспортную отрасль «Интернет вещей» проникает весьма интенсивно и заметно. В последние десятилетия число транспортных средств, особенно автомобилей, в России выросло в несколько раз. В таких условиях невозможно обойтись без удаленного цифрового мониторинга. Крупные мегаполисы мира (Барселона, Дубай, Москва и др.) активно используют технологии ІоТ для решения вопросов автоматизации и контроля систем общественного транспорта, парковок [7]. Благодаря смартфонам созданы системы мониторинга загруженности дорог на картах Яндекс, Google и др. Построены цифровые экосистемы программных решений (Яндекс Такси, Get Taxi и др.) [2]. Системы интеллектуального мониторинга транспорта с использованием ГЛОНАCC/GPS позволяют в 
постоянном режиме отслеживать целевое использование транспорта, маршруты движения, расход топлива. Роботизация в складской логистике становится конкретной реальностью, и все больше компаний внедряют складские интеллектуальные системы, управляемые с помощью Іо Т. Интегрированные в цепочку создания стоимости клиентов 3PL и 4PL - провайдеры посредством IоT и встроенной системы анализа и прогнозирования получают возможность в режиме онлайн оптимизировать загрузку физических активов, формировать и планировать оптимальные маршруты доставки. В России на государственном уровне нормативно закреплена обязанность перевозчиков устанавливать системы дистанционного мониторинга и контроля движения транспорта для коммерческих перевозок пассажиров и доставки опасных грузов [6].

Умные решения для транспорта и логистики посредством ІоТ-технологий позволяют обобщенно решать следующие задачи:

- автоматизация транспорта и управление беспилотным - безэкипажным транспортом;

- мониторинг маршрутов;

- уведомление о траффике;

- мониторинг инфраструктуры, получение телеметрических данных о состоянии транспортных средств и грузов;

- наблюдение за загруженностью транспортных сетей, магистралей;

- отслеживание местоположения, передвижения транспортных средств;

- мониторинг сообщений и коммуникаций на стыке различных видов транспорта;

- создание и развитие единой информационной телекоммуникационной среды транспортного комплекса в России [3].

На железнодорожном транспорте взаимодействие физических объектов и устройств можно рассматривать по следующим направлениям:

- межвагонная коммуникация;

- внутривагонная коммуникация;

- коммуникации в цепочке железнодорожный состав - инфраструктура;

- взаимодействие объектов внутри инфраструктуры;

- сенсорные и беспроводные системы связи.

Статистика Росстата [4] позволяет оценить масштабы распространения отдельных цифровых технологий, связанных с Интернетом вещей, в российском транспортном комплексе, в том числе в сфере железнодорожного транспорта.
По рисунку 1 видим относительные достижения и слабые стороны в части распространения цифровых технологий по видам экономической деятельности «транспортирование и хранение», в том числе «железнодорожный транспорт». Высокий уровень в целом по транспорту характеризует применение: систем мониторинга и управления (их применяли в 2019 г. 16,1\% транспортных организаций); геоинформационных и навигационных системы (GIS) (8,4\%). На железнодорожном транспорте: систем сбора, хранения, обработки, анализа, моделирования и визуализации массивов данных $(6,4 \%)$; геоинформационных и навигационных системы (GIS) $(6,4 \%)$.

Значительное отставание в сравнении с общими макроэкономическими показателями отметим по внедрению на транспорте технологий автоматической идентификации объектов (RFID) (рисунок 1).

Основной функционал ІоТ на железнодорожном транспорте - проведение непрерывного прогнозного мониторинга и обеспечения постоянной диагностики материально-технической базы инфраструктуры и подвижного состава. IоT на железных дорогах будет объединять такие модули, как: сбор данных через сенсоры и датчики; подсистемы передачи аккумулированных данных через фиксированную, мобильную, спутниковую связь; генерирование, хранение и обработка данных; модуль управления устройствами, непрерывного анализа данных, обеспечения безопасности; подсистема принятия запрограммированных «умных» решений.

В холдинге «Российские железные дороги» в рамках стратегии цифровой трансформации OAО «РЖД» технология IоT сопровождает внедрение следующих проектов:

- «Цифровое депо», «Доверенная среда», «Умный локомотив» - эти проекты позволят компании иметь точное представление о текущем состоянии локомотивов посредством дистанционной автоматизированной диагностики; выполнять ремонтные работы не по нормативному графику, а по результатам предиктивной диагностики;

- «Автоматизированная диагностика инфраструктуры и вагонов», «Обслуживание по состоянию» - обеспечат проведение мониторинга инфраструктуры и обслуживание по фактическому состоянию [8].

Указанные проекты цифровизации «Россий- 


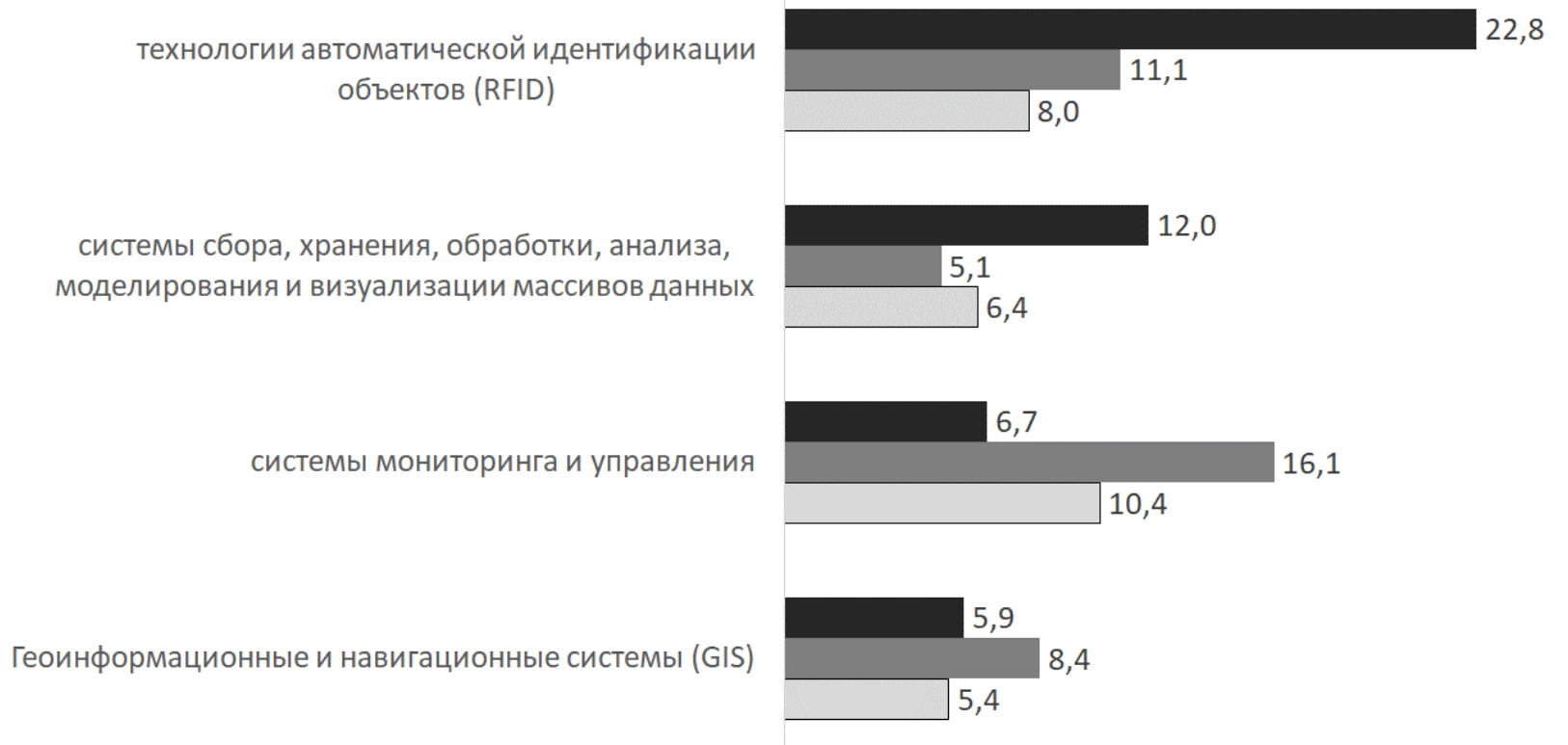

Предпринимательский сектор всего $\square$ Транспортирование и хранение $\square$ в т.ч. железнодорожный транспорт

Puc. 1. Доля (удельный вес) организаций, использовавших отдельные виды ключевых технологий цифровой экономики, связанных с Интернетом вещей, в 2019 г., в \% от общего числа обследованных Росстатом организаций Источник: построено автором на основе [4].

ских железных дорог» с экономической точки зрения будут способствовать снижению эксплуатационных расходов, сокращению затрат на проведение обслуживаний и ремонтов, сокращению внеплановых простоев и потерь от них.

\section{Заключение}

Технологии Интернета вещей имеют широкие возможности, реализация которых дает транспортным компаниям преимущества. Основной функционал ІоТ на железнодорожном транспорте заключается в проведении непре- рывного прогнозного мониторинга и обеспечения постоянной диагностики материальнотехнической базы инфраструктуры и подвижного состава. Проекты цифровизации «Российских железных дорог», среди которых «Цифровое депо», «Умный локомотив», «Автоматизированная диагностика инфраструктуры и вагонов» и ряд других, с экономической точки зрения, будут способствовать снижению эксплуатационных расходов, сокращению затрат на проведение обслуживаний и ремонтов, сокращению внеплановых простоев и потерь от них.

\section{Библиографический список}

1. Zhuravleva N.A., Wright J., Michalkova L., Musa H. Sustainable urban planning and Internet of things-enabled Big Data analytics: designing, implementing, and operating smart management systems // Geopolitics, History, and International Relations. 2020. T. 12. № 1. C. 59-65.

2. Волкова E.M. Закономерности развития и новые характеристики современных транспортных систем // Развитие экономической науки на транспорте: экономическая основа будущего транспортных систем: сб. научных статей VII международной научно-практической конференции; под ред. Н.А. Журавлевой. 2019. С. $190-196$.

3. Восемь ключевых технологий «Интернет вещей»: исследование PriceWaterhouseCoopers, октябрь 2017 г. [Электронный ресурc]. URL: https://www.pwc.ru.

4. ЕМИСС Государственная статистика: Официальные статистические показатели [Электронный ресурс] [EMISS State statistics: Official statistical indicators [Net recourse] (in Russ.)]. Доступно по: https://fedstat.ru. 
5. Об утверждении концепции построения и развития узкополосных беспроводных сетей связи «Интернета вещей» на территории Российской Федерации: приказ Министерства цифрового развития, связи и массовых коммуникаций РФ от 29.03.2019 г. № 113 [Электронный ресурс]. URL: https://digital.gov.ru/ru/ documents/6410.

6. Перспективы развития «Интернета вещей» в России [Электронный ресурc]. URL: https://www.pwc.ru.

7. Применение технологий Интернета вещей для развития современной городской среды: исследование PriceWaterhouseCoopers, 2018 г. [Электронный ресурc]. URL: https://www.pwc.ru.

8. Чаркин Е.И. О реализации стратегии цифровой трансформации ОАО «РЖД» // Железнодорожный транспорт. 2020. № 2. С. 66-70. 